\title{
Árguinas II (SEgorbe, CASTELlón): un CENTRO DE PRODUCCIÓN CERÁMico IBÉRICO
}

\author{
Árguinas II (Segorbe, Castellón, Spain): an Iberian Pottery Production Centre
}

MARÍA DE LAS MERCEDES FUENTES ALBERO ${ }^{1}$, JOAN GARIBO BODÍ ${ }^{2}$, LUIS LOZANO PÉREZ ${ }^{3}$, AMPARO VALCÁRCEL ESTORS ${ }^{4}$

(1) IES Clot del Moro (Sagunt).m.mercedes.fuentes@uv.es

(2) SArq-Serveis d'Arqueologia. joan@sarq.es

(3) SArq-Serveis d'Arqueologia. lozanoperezluis@gmail.com

(4) SArq-Serveis d'Arqueologia. amparo@sarq.es

\section{Resumen:}

Diversas intervenciones arqueológicas realizadas en las últimas décadas en la zona de Segorbe (Castellón) han aportado numerosos hallazgos relacionados con yacimientos correspondientes al periodo ibérico. Entre ellos destaca el de Árguinas II, objeto de estudio en este artículo, que en base a los restos recogidos en sucesivas prospecciones permiten identificarlo como un centro alfarero ibérico cuyo momento de máxima producción se sitúa entre los ss. IV-III a.C.

Palabras clave: periodo ibérico, prospección, cerámica, horno, Segorbe.

Abstract:

Over the last twenty years a cluster of archaeological works in Segorbe (Castellón) have provided large quantities of Iron Age sites. One of these sites is Árguinas II. The materials found, specially wastes, suggest the existence of an Iron Age pottery kiln. The highest pottery production was during the IV-III century B.C.

Key words: Iron Age, survey, pottery, kiln, Segorbe. 
En este artículo presentamos los materiales de uno de los yacimientos ibéricos existentes en la comarca del Alto Palancia (Castellón). Las intervenciones arqueológicas llevadas a cabo en la zona, correspondientes a ese período cronológico, son escasas y la mayoría de los datos obtenidos proceden de las prospecciones realizadas por V. Palomar en los años 80 , de otras vinculadas a explotaciones mineras y de diferentes proyectos de envergadura, tal es el caso del nuevo trazado para el tramo del corredor ferroviario de altas prestaciones que conectará Teruel con Sagunt (Busquier 2011), la construcción de la autovía Mudejar A-23 o la instalación de parques eólicos (Fernández 2008a; 2008b). No obstante, en pocas ocasiones han visto la luz los resultados obtenidos, caso del yacimiento del Rubial (Chóvar) (García y Moraño 1998).

Los yacimientos en los que se han realizado trabajos de excavación son: Peña de las Majadas (El Toro) (Sarrión 1978), La Torre del Prospinal (Pina de Montalgrao) (Cura y Falomir 2002-2003), El Cantal (Altura), La cueva del Murciélago (Altura) (Palomar 1986; 1989), Gola de Laguna (Segorbe), Torre de Mal Paso (Castellnovo) (Fletcher 1954; Martí y Selma 2008), Rochina (Sot de Ferrer) (Fletcher 1940) y El Alto de la Fuente (Sot de Ferrer). De entre todos ellos, solamente se ha exhumado completamente el poblado de Rochina, cuya arquitectura ha sido recientemente objeto de revisión y estudio (Llop 2015).
Por otra parte, existen una serie de trabajos que deben ser tenidos en cuenta en el estudio de la comarca. Tal es el caso de los dedicados al poblamiento (Járrega 1998; 2000; Palomar 1984; Pérez Mínguez 2006: 14-15), así como los centrados en diferentes cuevas-santuario ibéricas (Palomar 1986; 1989; 1991; Palomar y Oliver 1985), exvotos (Palomar 1995) o inscripciones de ese momento (Palomar y Oliver 1980). A ellos debemos sumar otros más generales que abordan este área geográfica en época ibérica de manera tangencial, bien sobre las cuevas-santuario (González-Alcalde 2002-2003; 2009; Moneo 2003) o las estructuras defensivas documentadas (Díes 1991: 178; Gusi et al. 1991; Moret 1996: 451; Uroz 1983).

En cualquier caso, a pesar de ser una zona a la que se le ha prestado poca atención en la bibliografía existente sobre la cultura ibérica, tiene gran potencial y esperamos que en los próximos años comiencen a publicarse los estudios que, aunque en estado incipiente, se están realizando sobre yacimientos concretos o sobre la estructuración y evolución del territorio.

\section{MARCO GEOGRÁFICO}

La comarca del Alto Palancia toma el nombre del río que nace y discurre por sus tierras, el Palancia. Queda delimitada orográficamente al $\mathrm{N}$ por la sierra de la Espina

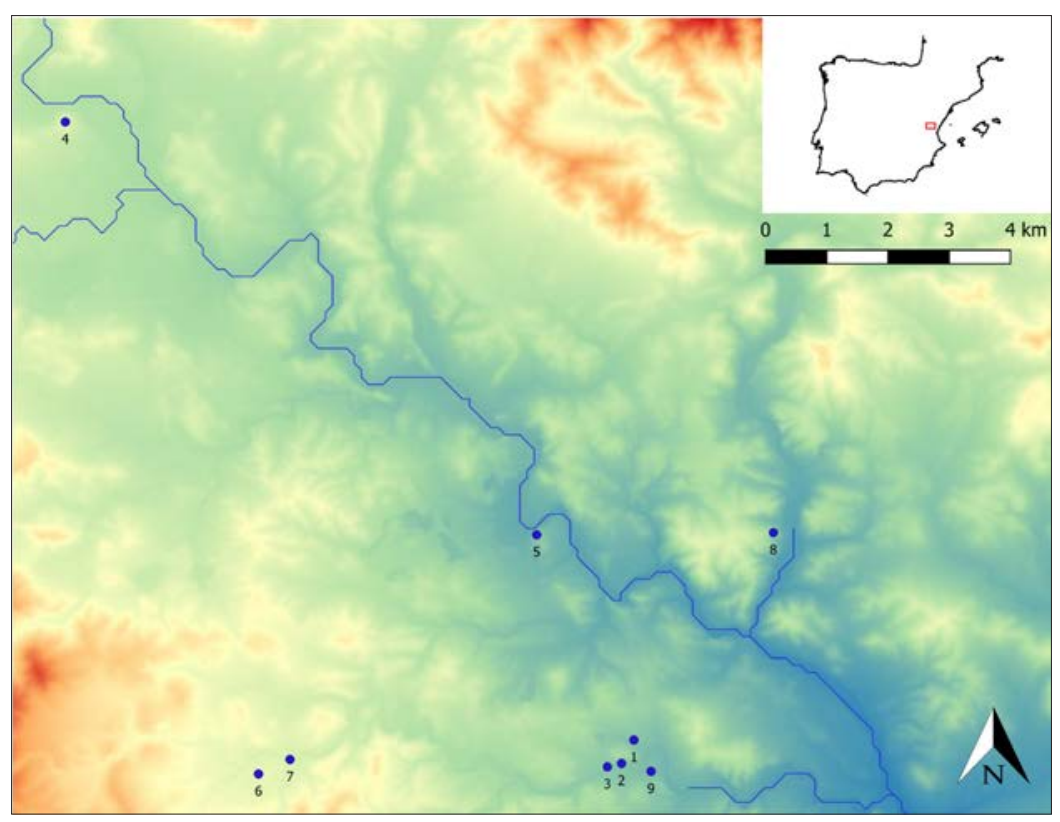

Fig. 1: Situación de Árguinas II (1) y otros yacimientos en los que se han recuperado ánforas con borde plano de este alfar: Árguinas III (2), Árguinas IV (3), Cerro de Sopeña (4), Alto de la Fuente (5), Somat 1 (6), Somat 11 o Corral del Cotorro (7), El Picacho (8) y Masía de Árguinas (9). 
y de Espadán, así como la de Andilla y la Calderona al S, existiendo entre ellas un fértil valle que resulta muy apto para su explotación agrícola y ganadera. Así las cosas, nos encontramos ante un espacio de contrastes (a nivel climático y paisajístico), donde resultan visibles las diferencias existentes entre las zonas del valle y la montaña.

Su ubicación próxima al litoral mediterráneo y al altiplano turolense, unido a las características del relieve, propician que a lo largo del tiempo haya sido una zona de paso, contacto y comunicación (Casabó y Rovira 2002: 9).

En época romana había una calzada que conectaba Saguntum (Sagunt) y Caesaraugusta (Zaragoza) (Arasa 1992: 45-46; Járrega 2000: 192-199; 2001), cuyo trayecto discurre por la zona y está bien definido por la presencia de carriladas en algunos afloramientos rocosos (Arasa y Roselló 1995: 76). Es muy probable que fosilice un camino anterior, tal vez ibérico, pues pasa muy próxima al yacimiento de Árguinas II (a 350 m en línea recta). Además, coincide en muchos puntos con el trazado de la antigua carretera N-234 (Pérez Mínguez 2006: 41-42; Sanchís 2000).

En la Edad Media se tiene noticia de la existencia de una Cañada Real que conectaba el reino de Aragón con el de València. A la altura del puerto del Ragudo se bifurca en un camino que conduce a Vall d'Uixó y Sagunt, siguiendo el curso del río Palancia (la distancia entre ese punto y el yacimiento de Árguinas II es de aproximadamente $2 \mathrm{~km}$ en línea recta), mientras que el otro se dirige hacia el río Turia tras atravesar la cabecera del Palancia. Esta ruta actualmente se sigue utilizando para la trashumancia entre los pastos del litoral valenciano y los de las tierras aragonesas (Farnós 1995).

Además, es probable que también hubiera vías de comunicación de menor importancia que aprovecharan los pasos naturales entre las zonas montañosas y permitieran la unión con la zona de Vall d'Uixó y Almenara, siguiendo trazados similares a las actuales carreteras N-225 y CV-320.

\section{EL YACIMIENTO Y SU ENTORNO}

\section{ÁRGUINAS II}

El yacimiento objeto de estudio se localiza en el extremo meridional del término municipal de Segorbe (Castellón), concretamente en una suave ladera de la partida de Árguinas, muy próxima al barranco homónimo (figs. 1 y 2). Se sitúa a $230 \mathrm{~m}$ sobre el nivel del mar, en una zona en la que el valle del Palancia se ensancha y

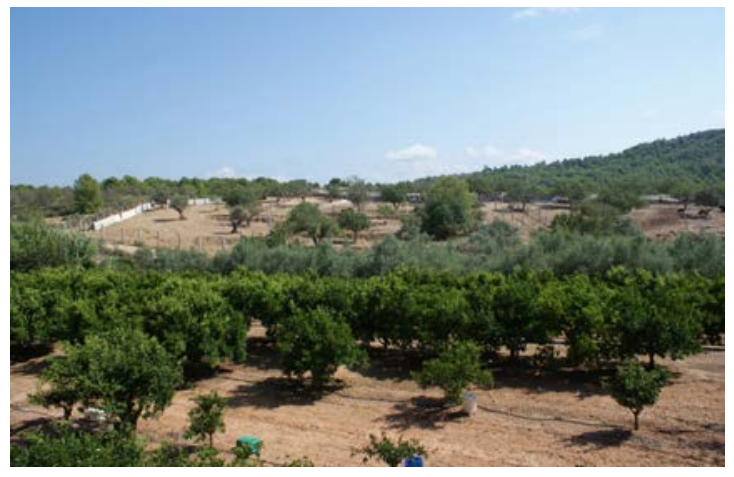

Fig. 2: Vista actual del yacimiento.

permite la comunicación con el extremo meridional de la Plana Baja, en la actual confluencia de las carreteras A-23 y N-225.

Se tenía noticia de su existencia por fuentes orales, pero fue V. Palomar, arqueólogo municipal de Segorbe, quien en los años 90 visitó la zona para confirmarlo y, en base a los materiales recogidos en superficie (cerámica pasada de cocción y una pella de barro cocida con digitoglifos marcados), propuso su identificación como un posible alfar ibérico.

En 2003, ante la futura explotación de la zona como cantera de yeso, se realizó una prospección sistemática que permitió: delimitar su tamaño $\left(3700 \mathrm{~m}^{2}\right)$, recuperar mayor volumen de materiales, identificar posibles estructuras y apreciar en superficie coloraciones cenicientas que podrían remitir al espacio de combustión.

En la última visita realizada al yacimiento, en 2015, dichas coloraciones resultaban inapreciables a nivel superficial, así como las supuestas estructuras. Además, al revisar el área de dispersión de los materiales se documentaron fragmentos cerámicos a ambos lados del pequeño ramal del barranco que discurre por la zona, en una superficie de unos $10.000 \mathrm{~m}^{2}$. Sin embargo, la mayor concentración cerámica se adscribe a una única parcela que ocupa $1500 \mathrm{~m}^{2}$. Por otra parte, la recuperación de restos de adobe quemados, probablemente pertenecientes a la cámara de combustión, así como de piedras rubefactadas y cerámicas con defectos de cocción (deformadas y vitrificadas), permite confirmar la existencia en ese espacio de un alfar.

Actualmente la zona está dedicada a campos de cultivo y algunos de ellos albergan reses bravas, lo que impide acceder libremente a la parcela que, además, está vallada. La utilización actual del terreno ha afectado negativamente a la conservación de los restos. 


\section{RECURSOS NATURALES}

En cuanto a los recursos naturales próximos a la zona en la que se ubica el yacimiento, señalar que geológicamente el terreno está formado por afloramientos de arcillas margosas de aspecto pizarreño, arcillas con yesos grises y cuarzos, así como por depósitos de pie de monte constituidos por arcillas rojas con cantos encostrados junto al barranco de Árguinas, por lo que es más que probable que el abastecimiento de arcilla se realizara en su entorno inmediato.

El recurso hídrico más cercano al enclave es el citado barranco (a $200 \mathrm{~m}$ ), que desemboca en el río Palancia, del que dista $2 \mathrm{~km}$ en línea recta. Aunque actualmente constituye un curso de agua intermitente de pequeña entidad, que se nutre fundamentalmente de los aportes pluviosos estacionales, es probable que en época ibérica fuera más continuado.

Respecto al combustible vegetal, en el entorno inmediato encontramos áreas montañosas que forman parte de las estribaciones de la sierra de la Calderona (al SO) y constituyen una fuente inagotable de recursos, tal es el caso de los árboles, matorrales y monte bajo propios del paisaje mediterráneo, hoy por hoy muy degradado como consecuencia de la antropización y de distintos incendios forestales que han afectado a la zona. Actualmente existen pinares (Pinus halepensis y Pinus pinaster) con algunos ejemplares de carrasca (Quercus ilex sp. Rotundifolia), olivos (Olea auropaea), almendros (Prunus dulcis) y algarrobos (Certonia siliqua), así como diversos tipos de matorrales: aliagas (Ulex parviflora), coscojas (Quercus coccifera), jaras (Cistus albidus), lentiscos (Pistacea

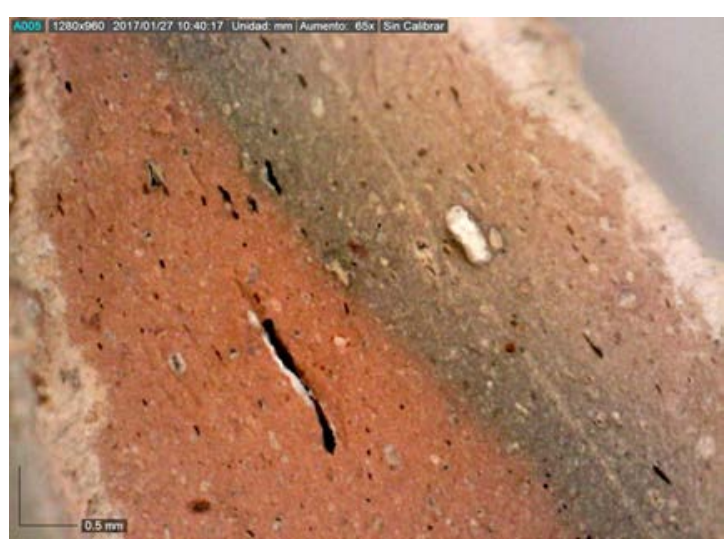

Fig. 3: Detalle de la pasta. Foto de M. Blasco. lentiscus), retamas locas (Osyris alba), cantuesos (Lavandula stoechas), esparragueras (Asparagus acutifolius) y romeros (Rosmarinus officinalis). No obstante, su vegetación natural estaba formada por alcornocales (Quercus suber) con su sotobosque característico: brezos (Erica multiflora, Erica arbórea, Erica ecoparia), estepas (Cistus salvifolius, Cistus albidus), madroños (Arbustus unedo), culantrillos (Asplenium onopteris), zarzaparrillas (Smilax aspera), hiedras (Hedera helix), ruscos (Ruscus aculeatus), rubias peregrin y flámulas (Clematis flammula) (Altur 2008).

En la elección del lugar en el que establecer los centros alfareros primaba la cercanía al área de captación de los recursos naturales necesarios para la producción de cerámica, fundamentalmente el agua, frente a la proximidad a las vías de comunicación y a los posibles consumidores, como se ha visto en otras ocasiones (Coll 2000: 192; Duarte et al. 2000: 237-238; López Seguí 2000: 247; Lozano 2006: 135). Si bien es cierto que en el caso de Árguinas II confluyen todas estas características, pues además de su proximidad al barranco y a diferentes caminos, existen varios núcleos poblacionales relativamente cercanos de similar cronología. Parece que estos yacimientos, de reducidas dimensiones, pudieron estar especializados en la explotación de ciertos recursos agropecuarios, formando parte de un territorio articulado en torno a un lugar central identificado con El Cerro de Sopeña (Segorbe) (Mata 2002: fig. 4), que ejercería un control sobre este tipo de enclaves.

\section{CARACTERIZACIÓN DE LA PRODUCCIÓN}

Para el estudio, clasificación y caracterización de la producción se han seguido los criterios establecidos en el ensayo de tipología que sobre cerámica ibérica realizaron C. Mata y H. Bonet (1992).

La casi totalidad de fragmentos recuperados pertenecen a la clase A. El tipo de cocción que predomina es la oxidante, aunque también está documentada la alternante y la reductora. Las pastas son compactas y el desgrasante muchas veces se observa a simple vista, especialmente el más característico, de color negruzco (fig. 3). Las superficies exteriores no están bruñidas ni presentan barbotina y algunos ejemplares se decoran con motivos geométricos realizados con óxido de hierro.

Los tipos identificados son variados (fig. 4): ánforas, tinajas y tinajillas sin hombro, lebetes, kalathoi, jarros, caliciformes, platos, cuencos, soportes, morteros, pondera y 
Fig. 4: Tipos cerámicos identificados en el yacimiento de Árguinas II.

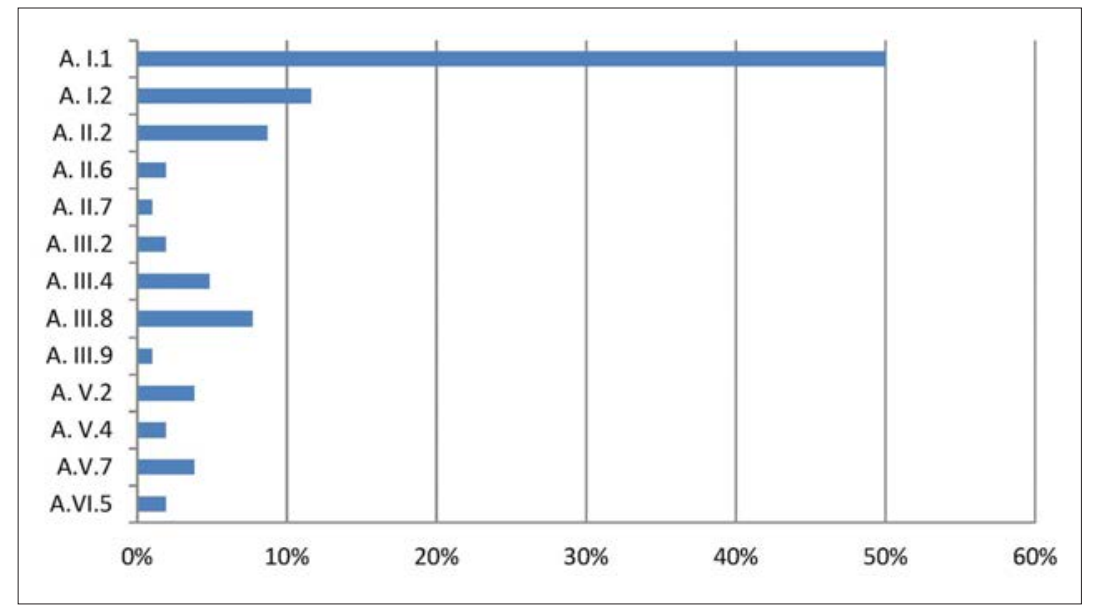

cráteras. Si bien, los más característicos son las ánforas con borde plano, los soportes relativamente estrechos y las cráteras de cuello cilíndrico similares al tipo PP6 de Pla de Piquer (Alfara de Algimia) (Aranegui y Martí 1995: 137-139).

A continuación presentamos una breve descripción de cada uno de los tipos, deteniéndonos en aquellos que destacan por su excepcionalidad, siempre teniendo en cuenta que la muestra con la que se trabaja está sesgada, pues los materiales proceden únicamente de prospección y algunas de las formas documentadas se conservan bastante incompletas.

\section{ÁNFORAS (A. I.1) (fig. 5)}

Recipientes profundos, con cuerpo alargado y boca estrecha, que portan dos asas de sección circular dispuestas en vertical en el cuerpo de la pieza, tras el hombro. Estaban destinadas al transporte y almacenaje de productos líquidos o sólidos (Diloli 2008: 241; Ribera y Tsantini 2008).

Constituyen la forma más abundante y característica de la producción, si bien, a pesar de que entre el material recuperado se han identificado dos tipos de borde: el alto y engrosado por el interior, así como el plano, predomina claramente este último.

Los ejemplares recogidos de ánforas sin cuello y boca plana pueden presentar el borde sin diferenciar externamente (fig. 5, 5 y 8), o tenerlo levemente marcado con un rehundido (fig. 5, 1-4 y 7) o un suave resalte previo a su inicio (fig. 5, 6). Los bordes poseen, además, un ligero engrosamiento interno que puede estar más o menos pronunciado. Los diámetros de apertura de la boca oscilan entre los 8,5-13 cm, aunque predominan los que miden $10 \mathrm{~cm}$. En alguna ocasión se ha planteado la posibilidad de que esta forma de la boca, en continuidad con el perfil de la pieza y sin resaltes, estuviera ligada al cierre de la misma, que se efectuaría con tapaderas de diferentes materias (Miró 1984: 180).

En el borde de una de las piezas existen dos líneas incisas precocción que constituyen una marca anepigráfica (fig. 5, 9). Su realización cuando la arcilla todavía estaba fresca nos permite señalar como autor de la misma al alfarero (Soria y Mata 2015: 152). Al localizarse en la parte interior del borde resultaría poco visible, más teniendo en cuenta que la tapa del ánfora la cubriría parcial o totalmente, por lo que su presencia no debe estar vinculada a la identificación del contenido, procedencia, propietario o destino del ánfora.

En los ejemplares conservados más enteros se aprecia que el hombro tiene forma redondeada. Llama la atención algún caso en el que éste aparece sobreelevado y la boca rehundida (fig. 5, 7 y 8), recordando formalmente a una variante de producción layetana (Balsera 2007).

No se ha conservado ninguna pieza de este tipo completa, ni tan siquiera la parte inferior de la misma o, al menos, no se ha podido identificar, por lo que hasta el momento se desconoce cómo sería y si portaba o no pivote, aunque lo cierto es que tampoco se han recuperado ejemplares de este elemento macizo. Cabe aludir a una pieza de pequeño formato (de $12 \mathrm{~cm}$ de alto) hallada en el cercano poblado de Rochina (Sot de Ferrer), cuyo paradero actual es desconocido. Aparentemente tiene el borde plano, el cuerpo cilíndrico y su base acaba en pivote (Fletcher 1940: 131 y 134, lám. XIX.2), por lo que ¿podría tratarse de una fabricación en tamaño reducido de las ánforas características de este centro de producción? 
María de las Mercedes Fuentes Albero, Joan Garibo Bodí, Luis Lozano Pérez, Amparo Valcárcel Estors

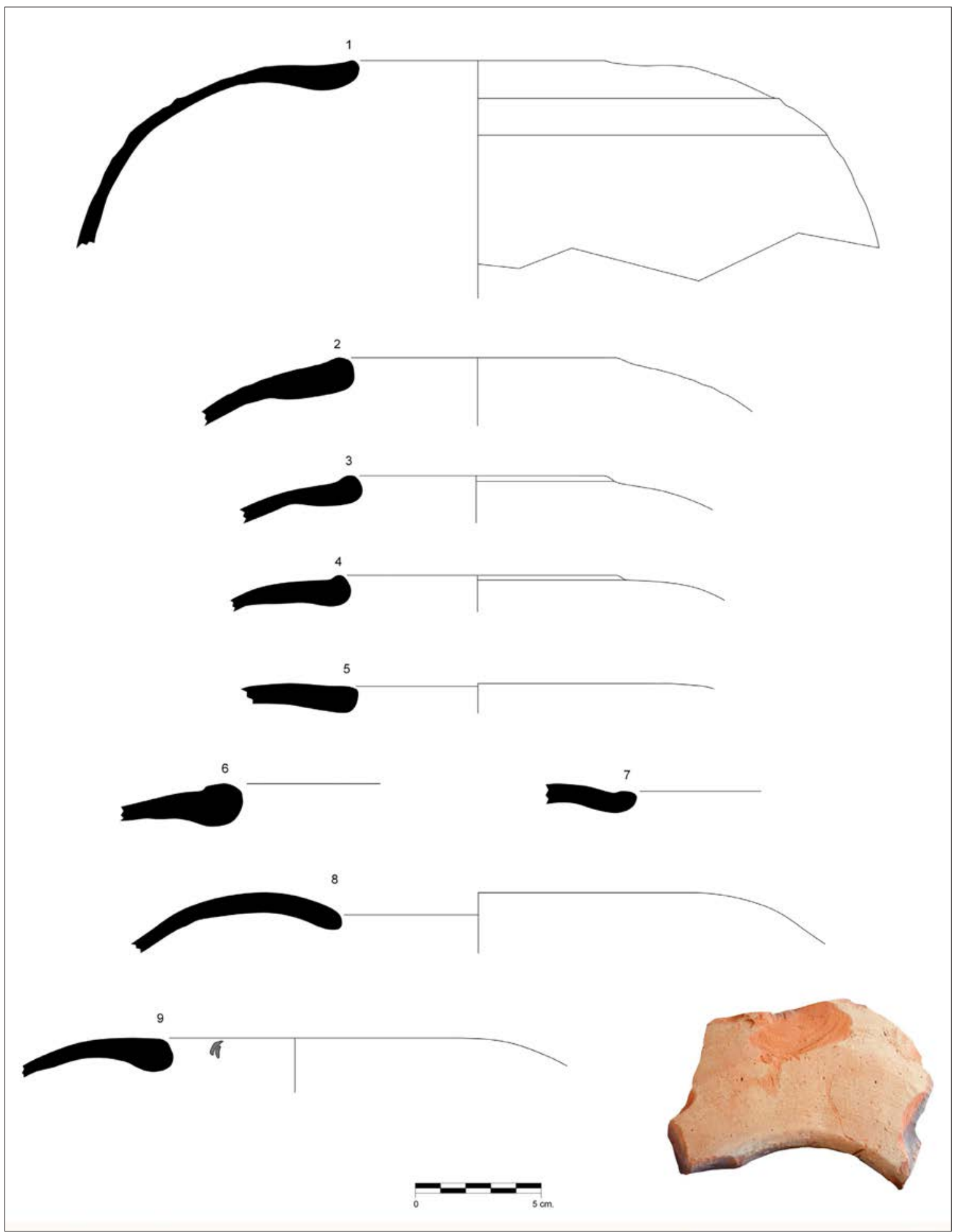

Fig. 5: Ánforas con borde plano. 
Las ánforas del tipo I-8, repertoriadas en el vecino territorio de Arse, sí presentan pivote y están datadas entre los ss. III-I a.C., aunque sus bordes difieren de los que aquí presentamos, pues son entrantes y engrosados (Ribera 1982: 107; Aranegui 2004: 50-51). Se han localizado ejemplares de esta variedad saguntina en Ruaya (València), con una cronología de la segunda mitad del s. III a.C., y en Alorda Park (Calafell) (Ribera y Tsantini 2008: 624 y 630). También se han atestiguado pivotes macizos en: El Castellet de Bernabé (Llíria) (Guérin 2003: 82 y 146, fig. 122, 377; fig. 221, 651), El Puntal dels Llops (Olocau) (Bonet y Mata 2002: 129), El Rabosero (Torres-Torres) (Martí 1998: 201), La Punta d'Orleyl (Vall d'Uixó), El Castell d'Almenara (Almenara) (Ribera 1982: 37; Oliver et al. 1984: fig. 26, 1) y El Tossal de la Balaguera (La Pobla Tornesa) (Allepuz 2001: fig. 73, 10). En este sentido, cabe señalar que en otros yacimientos del Alto Palancia: El Cerro de Sopeña (Segorbe), El Picacho (Soneja), Montecillo de Árguinas (Segorbe) y Las Torrecillas (Altura), también se ha localizado algún ejemplar de esa parte característica, pero como no se ha recuperado ningún perfil completo de ánfora, no se puede establecer de manera objetiva una asociación entre ánfora con borde plano y pivote.

En cualquier caso, los yacimientos próximos al valle del Palancia en los que se han documentado ánforas con borde plano son: el Grau Vell (Aranegui 2004: fig. 1, 10) y Ponera (Sagunt) (Martí 1998: fig. VI, 40), El Rabosero (Torres-Torres) (Gil-Mascarell y Aranegui 1977: fig. 1, 2 y 11), Riera (Alfara de Algimia) (mediados del s. III a.C.) (Aranegui 2004: 49), El Picacho (Soneja), El Alto de la Fuente (Sot de Ferrer), Cerro de Sopeña, Somat 1, Somat 11 o Corral del Cotorro, Árguinas III, Árguinas IV y Masía de Árguinas (Segorbe). En territorios próximos también existen ejemplares en: La Costa (Cabanes) (Allepuz 2001: fig. 23, 9), El Castell (Oropesa), El Racó de Bernardino (La Pobla Tornesa) (Allepuz 2001: fig. 23, 4), El Tossal de la Balaguera (La Pobla Tornesa) (Allepuz 2001: fig. 23, 6), Vinarragell (Borriana) (Mesado 1974: 72 y 79, figs. 39, 512 y 44, 6; Ribera 1982: fig. 2, 1), El Solaig (Betxí) (Fletcher y Mesado 1967: fig. 5, 1-2 y 5, 4-5), Sant Josep (Vall d'Uixó) (Oliver et al. 1984: 80; Viciach y Rovira e.p.), La Punta de Orleyl (Vall d'Uixó) (Oliver et al. 1984: figs. 15, 5 y 17, 9), El Puntal dels Llops (Olocau) (Bonet y Mata 2002: 129, fig. 97, 13008), Tossal de Sant Miquel (Llíria) (Bonet 1995: 218, fig. 107, 362-D.77), Ruaya (Albelda 2015: fig. 8, 2) y Valentia (València) (Garibo 2006).
La cronología de uso de este tipo de borde en las ánforas, por tanto, es amplia, pues abarca desde el s. IV a.C., o incluso un poco antes, hasta el primer cuarto del s. I a.C., pues se ha documentado en el solar de L'Almoina (València) tanto en los niveles de fundación (Álvarez et al. 2003, pieza 60690-41) como en los niveles correspondientes a la destrucción de Valentia durante las Guerras Sertorianas, en el 75 a.C. (Pascual y Ribera 1991; Ribera 1993, pieza 6961-6).

TINAJAS (A.I.2) (figs. 6 y 8)

Recipientes altos, profundos y cerrados que generalmente cuentan con un par de asas verticales dispuestas en su tercio superior y una base indicada o cóncava. Se utilizaban para el almacenaje o trasvase de líquidos o sólidos.

Constituye el segundo tipo más abundante dentro del conjunto cerámico repertoriado, si bien, todos los ejemplares corresponden al subtipo que carece de hombro (A. I.2.2). Existe escasa variabilidad en la forma del borde, pues excepto un ejemplar subtriangular, el resto son moldurados. El diámetro de apertura de la boca oscila entre los 27 y los $37 \mathrm{~cm}$, situándose la mayoría en la parte alta de la horquilla. Algunas piezas tienen el cuello diferenciado y un baquetón poco antes del inicio del cuerpo (figs. 6, 3; 8, 3).

En cuanto a la decoración, prácticamente la mitad de los ejemplares presentan bandas pintadas en el labio o en las paredes externas del cuerpo.

\section{TINAJILLAS (A.II.2) (fig. 6)}

Piezas formalmente similares a las tinajas, pero de menores dimensiones, que debieron utilizarse como recipientes de despensa.

Constituye el tercer tipo más habitual en el registro y todos los ejemplares identificados carecen de hombro (A. II.2.2). Pueden tener el labio moldurado (en ocasiones exvasado y con el cuello indicado), saliente o engrosado y el diámetro de la boca mide entre 17 y $24 \mathrm{~cm}$. Algunas piezas también presentan el baquetón por debajo del cuello y antes del cuerpo que se observa en las tinajas (fig. 6, 4).

La decoración, en los ejemplares que la llevan, consiste en bandas pintadas en el labio y/o la parte exterior del cuerpo.

\section{LEBETES (A.II.6)}

Vasija abierta y no muy profunda, de mediano o gran tamaño. El cuerpo adopta una forma globular y puede descansar sobre un pie o carecer de él. Su amplia boca los hace aptos para el trasiego de líquidos. 
María de las Mercedes Fuentes Albero, Joan Garibo Bodí, Luis Lozano Pérez, Amparo Valcárcel Estors

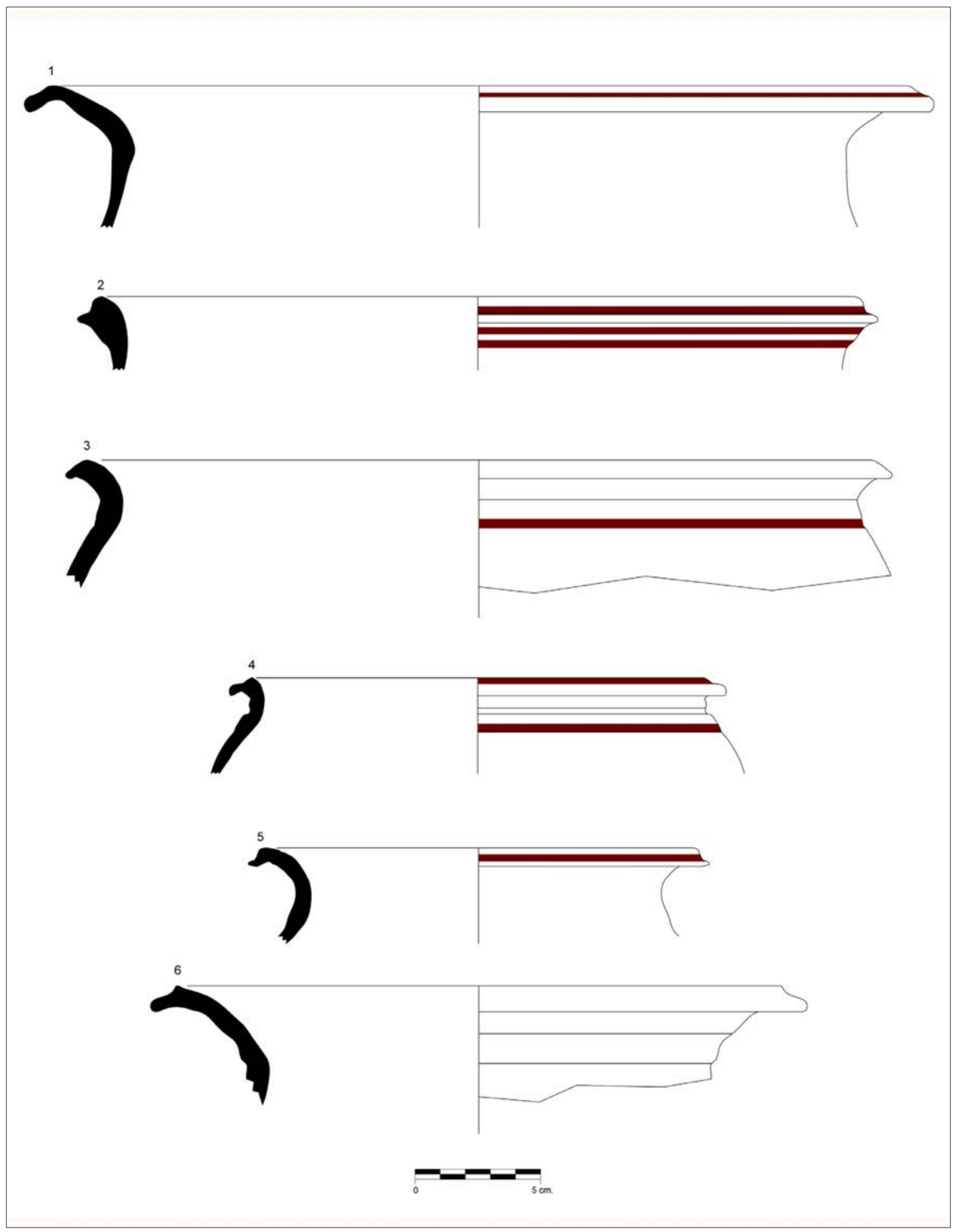

Fig. 6: Tinajas $(1 ; 2 ; 3)$ y tinajillas $(4 ; 5 ; 6)$. 


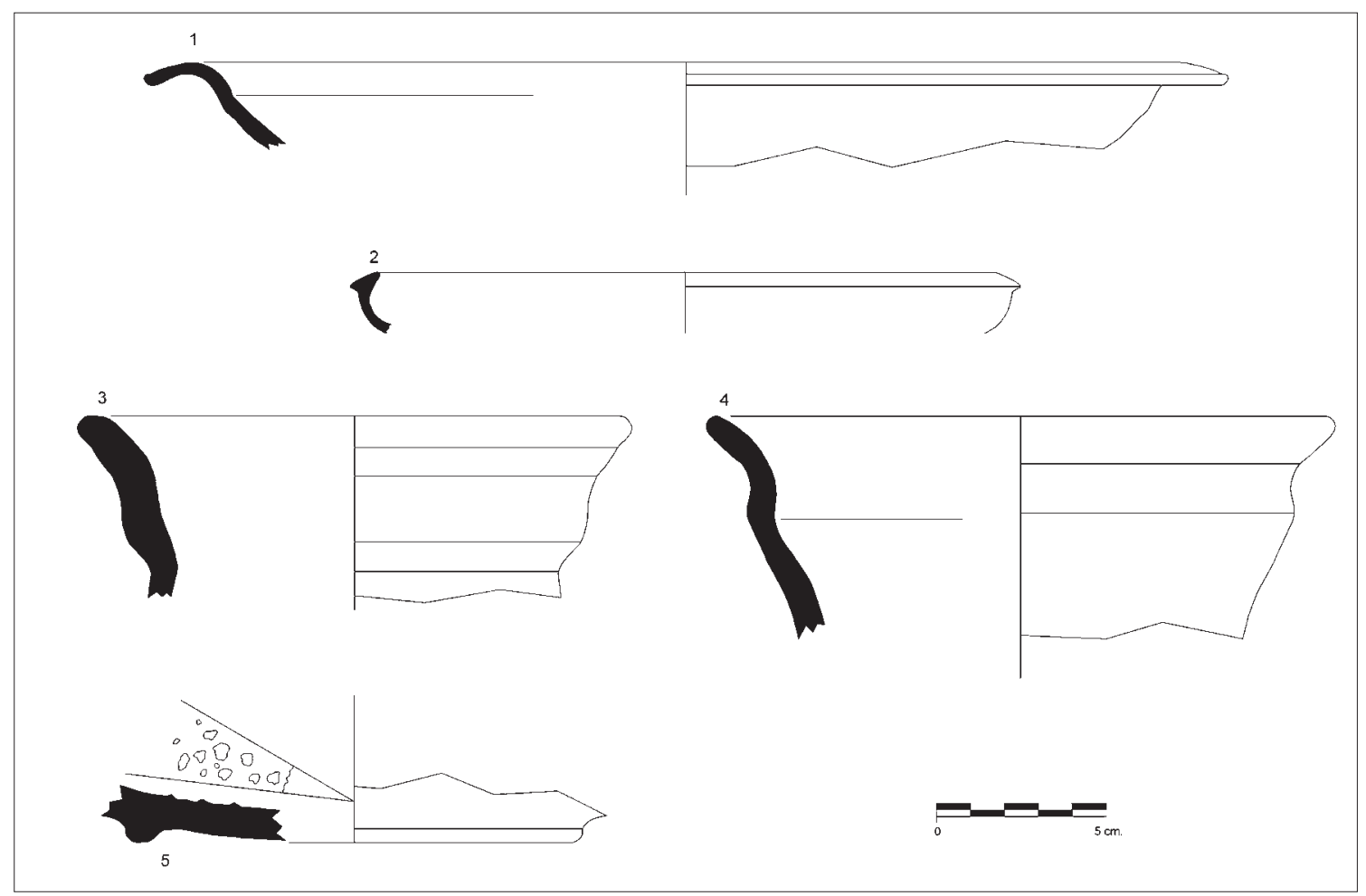

Fig. 7: Platos $(1 ; 2)$, soportes $(3 ; 4)$ y mortero (5).

Hemos identificado dos ejemplares entre las piezas estudiadas. Ambas poseen el labio moldurado y son de gran tamaño, pues el diámetro de sus bocas mide 37 y 45 cm. Ninguno presenta decoración.

\section{KALATHOI (A.II.7)}

Vasos abiertos y de profundidad media, cuyo cuerpo puede adoptar una forma cilíndrica o troncocónica, diferencia que marca los dos subtipos existentes. Suelen carecer de asas y sus bases son mayoritariamente cóncavas. Estos recipientes multifuncionales casi siempre están decorados y son de los pocos que se exportan fuera del ámbito peninsular.

Solamente hemos documentado un ejemplar con labio en ala plana ligeramente pendiente. Conserva escaso perfil del cuerpo, lo que impide adscribirlo a un subtipo determinado.

\section{JARROS (A.III.2)}

Piezas profundas y cerradas cuyas bocas tienen forma circular o lobulada. Portan un asa vertical que les facilita su utilización en el servicio de mesa, pues albergaban líquidos que se vertían en otros recipientes.

Hemos identificado dos individuos, uno de ellos con el labio saliente y un diámetro de $15 \mathrm{~cm}$.

\section{CALICIFORMES (A.III.4)}

Vasos abiertos, de pequeño tamaño, utilizados para contener líquidos. Presentan cuerpo globular con variantes en el perfil que se caracterizan por tener el cuello más o menos marcado y presentar una carena. No suelen llevar decoración.

Están escasamente representados. Todos los ejemplares tienen el labio saliente y en los casos en los que hemos podido calcular el diámetro de apertura de la boca mide $11 \mathrm{~cm}$.

\section{PLATOS (A.III.8) (fig. 7, 1 y 2)}

Recipientes abiertos y planos empleados en el servicio de mesa que, en base al tipo de borde que presentan, pueden clasificarse en diferentes variantes.

Entre el material estudiado, es el cuarto tipo más representado y carece de decoración. 
Hay seis ejemplares de plato con borde exvasado (A III.8.1). Todos tienen el labio saliente, salvo una pieza de pasta gris que presenta el borde inclinado y entrante (fig. 7 , 2). Los diámetros de las bocas van de los 18 a los $29 \mathrm{~cm}$.

Por otra parte, solamente aparecen dos páteras (A. III.8.2), una de las cuales tiene el borde entrante marcado con una carena.

\section{CUENCOS (A.III.9)}

Recipiente abierto de perfil hemisférico, con labio sin diferenciar, empleado en el servicio de mesa.

El único ejemplar identificado presenta un borde recto y un diámetro de boca de $13 \mathrm{~cm}$.

\section{SOPORTES (A.V.2) (fig. 7, 3 y 4)}

Piezas cilíndricas, abiertas por ambos extremos, que tienen escasa altura. Sus bocas cuentan con un diámetro de apertura que oscila entre $\operatorname{los} 15-18 \mathrm{~cm}$ y sus bordes son salientes. Las paredes del cuerpo describen una forma sinuosa (A.V.2.2), catalogada como moldurada. En los casos estudiados se aprecia que la arcilla con la que se confeccionan está bien depurada, sin recibir ningún tratamiento externo. Se disponían sobre una superficie regular, generalmente el suelo, para dar estabilidad a ciertas piezas con base muy pequeña o sin ella, caso de las ánforas. De ahí que la producción de ambas suela estar relacionada, es decir, se realicen en el mismo alfar.

Al comparar los soportes aquí presentados con los documentados en otros yacimientos ibéricos, se observa que estos tienen una altura ligeramente superior a lo que viene siendo habitual y el cuerpo es más estrecho, por lo que no sería descabellado suponer su adecuación a piezas con pivote.

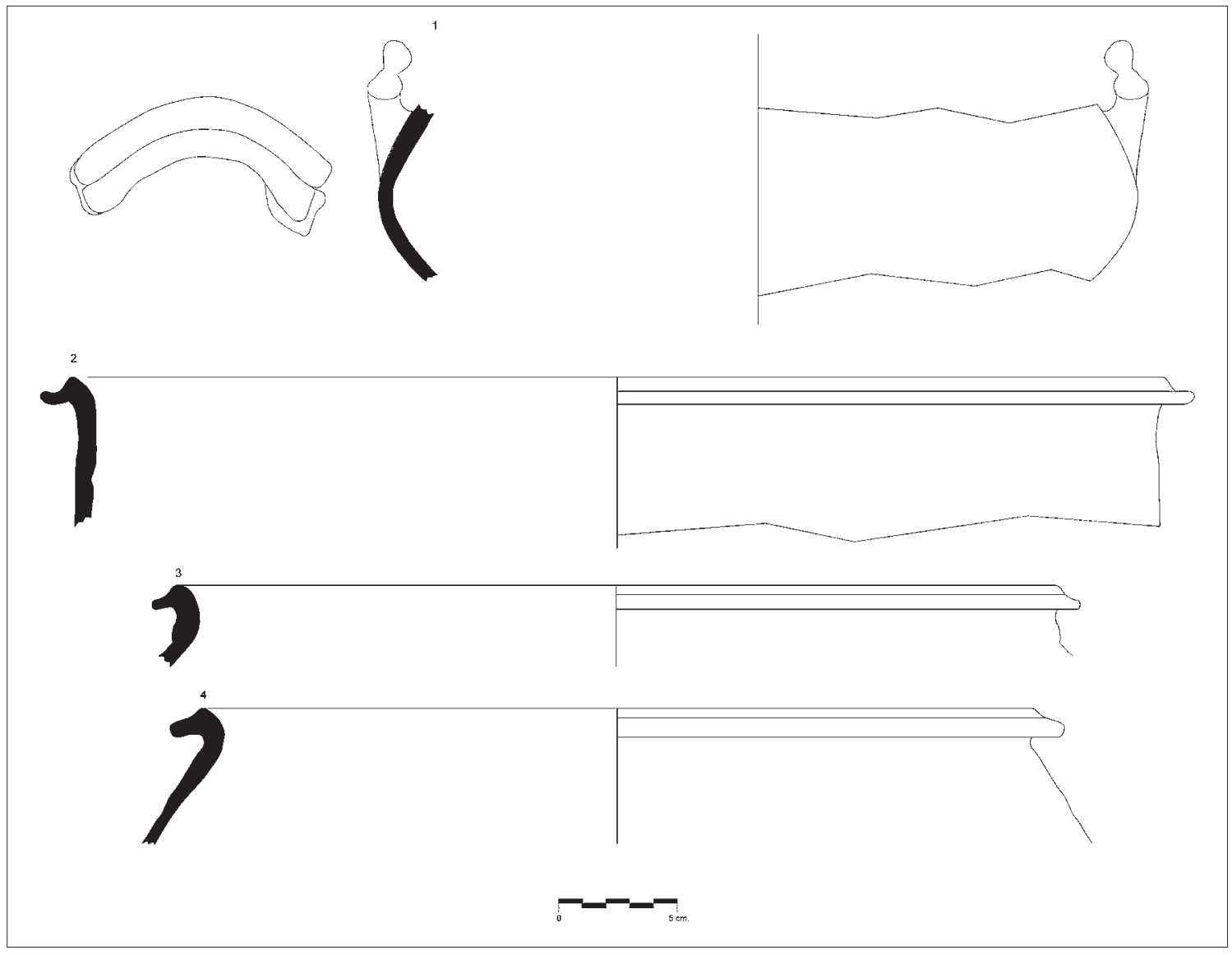

Fig. 8: Cráteras $(1 ; 2)$ y tinajas $(3 ; 4)$. 
Los soportes moldurados son bastante comunes en el Ibérico Pleno (Mata y Bonet 1992: 136).

\section{MORTEROS (A.V.4) (fig. 7, 5)}

Recipientes abiertos y poco profundos, con gruesas paredes, que se caracterizan por presentar en el fondo interno piedras incrustadas o estrías incisas que permiten machacar, con la ayuda de una mano de mortero, los productos en él depositados.

Solamente hemos recuperado dos ejemplares. Uno corresponde a la parte superior de la pieza, tiene el borde saliente con ala plana, mide $32 \mathrm{~cm}$ de diámetro y recuerda a modelos del horizonte antiguo. El otro pertenece a una parte inferior de un mortero con la base indicada, que mide 12,8 cm de diámetro, y tiene el fondo abrasivo ligeramente inclinado y compuesto de piedras de toba calcárea incrustadas en la arcilla.

\section{PONDERA (A.V.7)}

Se trata de elementos macizos utilizados como contrapesos, relacionados con pesas de telar. Todos llevan un orificio en la parte central superior para su suspensión y algunos pueden tener decoración a base de marcas incisas u orificios. Según sea su forma pueden adscribirse a varios subtipos.

De los cuatro ejemplares documentados, muy incompletos, tres tienen forma troncocónica (A. V.7.1) y otro paralelepipédico (A. V.7.3). Ninguno conserva decoración.

\section{CRÁTERAS (A.VI.5) (fig. 8, 1 y 2)}

Son pocos los ejemplares que aquí podemos incluir y, además, conservan escaso perfil. Una de las piezas corresponde a la parte superior del recipiente y se caracteriza por presentar un borde moldurado, gran diámetro de apertura de boca $(50 \mathrm{~cm}$ ) y cuello cilíndrico (fig. 8,2). La otra pertenece a la zona central de la pieza y porta asas dobles dispuestas en horizontal (fig. 8, 1).

Ejemplares con similar forma (PP6) están repertoriados en el horno de Pla de Piquer (Algimia de Alfara), donde se han individualizado dos variantes atendiendo a las dimensiones de la boca, pero no se han clasificado como pertenecientes a ningún tipo determinado (Aranegui y Martí 1995: 137). A pesar de su coincidencia formal, existen diferencias entre las piezas documentadas en Árguinas II y las del horno arsetano que permiten individualizar su producción. Tales características son: la ausencia del engobe blanquecino que poseen en las paredes externas las piezas de Pla de Piquer, el labio moldurado muy marcado, el borde saliente poco destacado, la ausencia de resalte en la zona donde empieza el cuello y la inexistencia de decoración.

Hay piezas similares en Tos Pelat (Moncada) (Burriel 1997: 74, fig. 3, 1 y 2), identificadas como tinajas por la tendencia no tan cilíndrica de sus paredes; en Tossal de Sant Miquel (Llíria) (Bonet y Mata 1997: 42, fig. 4, 17), donde la conservación de parte del desarrollo de su cuerpo permite asimilarlo a un vaso à chardon; y en La Seña (Villar del Arzobispo), que corresponde a una crátera (Bonet y Mata 1997: 43, fig. 7, 35).

\section{CONCLUSIONES}

Los materiales aquí analizados proceden del testar de un centro alfarero. Normalmente los desechos de cerámica se vertían y acumulaban en las proximidades de los hornos. La concentración de los restos induce a considerar este espacio como un área de trabajo especializado en la producción de recipientes cerámicos, diferenciado y aislado de la zona de hábitat, que podría localizarse en las inmediaciones.

Dado el gran volumen de recursos necesarios para llevar a cabo la actividad alfarera (Echallier y Montagu 1985), era recomendable buscar una ubicación cercana a las fuentes de combustible, agua y canteras de arcilla que facilitara su aprovisionamiento. Como hemos visto, el yacimiento se encuentra muy próximo al margen boscoso de la Sierra Calderona, en las inmediaciones de zonas con pendientes que no permiten su aprovechamiento para desarrollar actividades agrícolas y que incluso hoy en día se mantienen como bosque. También se ubica cerca del barranco de Árguinas, lugar en el que se abastecería de agua, y de los depósitos aluviales que se acumulan en el lecho de éste, donde resultaría fácil y cómodo proveerse de arcilla.

La abundancia de ejemplares correspondientes a una misma forma cerámica, ánforas carentes de cuello y con el borde sin diferenciar, permite deducir que se trata de una producción estandarizada, aunque con la variabilidad propia de cualquier producto artesanal realizado a mano. Aún así, no existe una producción especializada en un único tipo, pues también se han identificado: tinajas y tinajillas sin hombro, lebetes, kalathoi, jarros, caliciformes, platos, cuencos, tapaderas, morteros, soportes, pondera y cráteras. Esta amplia variedad tipológica y el escaso volumen que suponen los desechos de cerámica, reflejan la producción de un alfar que suministra el repertorio básico de piezas necesario para cubrir la demanda de la población del entorno. 
Rastrear la distribución de la producción de este alfar es tarea difícil, dado que el material disponible resulta sesgado, pues mayoritariamente procede de prospecciones puntuales y no se han efectuado análisis arqueométricos de las piezas, por lo que la dispersión que aquí se plantea es un simple esbozo de lo que debió ser su comercialización real (fig. 1). En este sentido, el tipo más característico que permite la aproximación a esta dimensión de estudio son las ánforas con borde plano, identificadas en mayor número en los yacimientos situados a poca distancia de Árguinas II, siendo el Cerro de Sopeña (Segorbe) el más alejado (a 11,5 km de distancia en línea recta). Durante mucho tiempo se consideró que se trataba de una producción propia de la costa catalana (Miró 1984; Sanmartí et al. 2004; Tsantini 2007), si bien, su hallazgo en hornos o centros alfareros del territorio de Arse, caso de Ponera (Sagunt) (ss. IV-III a.C.) y Riera (Alfara de Algimia) (mediados del s. III a.C.) (Aranegui 2004: 49-50), permitió rectificar dicho planteamiento. Su reciente localización en el yacimiento de Árguinas II, con características formales similares a las arsetanas, indica que este tipo de recipientes también era común en el valle del Palancia. Análisis de contenido practicados en ejemplares de la costa catalana muestran que portaban cerveza (Juan-Tresseras 2000: 141-143) o vino (Aguelo y Pons 2012: 12; Aguelo et al. 2013; Junyent y Baldellou 1972: 34).

Por último, apuntar el espacio temporal en el que estuvo en uso el alfar de Árguinas II. En base a las formas con gran diámetro de apertura de boca, asimilables a cráteras, que guardan cierto parecido con algunos ejemplares recuperados en Pla de Piquer (Algimia de Alfara), y a la datación de los alfares pertenecientes al territorio de Arse en los que se producen ánforas con borde plano (Aranegui 2004: 49-50; Aranegui y Martí 1995: 148), hemos podido estimar que su momento de máxima producción abarcaría los ss. IV-III a.C. Por otra parte, el hallazgo testimonial de tegulae y alguna pieza de cerámica común romana apuntan a una reutilización posterior de este espacio.

\section{AGRADECIMIENTOS}

Agradecemos a V. Palomar, director del Museo Municipal de Arqueología y Etnología de Segorbe, las facilidades proporcionadas para acceder al catálogo arqueológico del museo y estudiar los materiales recuperados en este yacimiento.
También damos las gracias a la profesora C. Mata, quien nos sugirió la idea de estudiar este yacimiento y nos orientó en distintos aspectos. Su ánimo y buena predisposición siempre nos han sido de gran ayuda.

Por último, y dado que en algunos casos se ha podido consultar documentación inédita, debemos citar la colaboración de A. Viciach, P. Pascual, A. Ribera, S. Selma y D. Sanfeliu.

\section{BIBLIOGRAFÍA}

ALBELDA, V. (2015): Ruaya: los iberos junto a la ciudad de València, El sucronensis sinus en época ibérica (C. Aranegui, ed.), Saguntum-PLAV Extra-17, València, 101-106.

AGUELO, X.; PONS, O. (2012): El derelicte de Binissafúller. Amics del Museu de Menorca, campanya del 2011, Imhotep 25, 11-12.

AGUELO, X.; PONS, O.; DE JUAN, C.; RAMON, J.; MATA, C.; SORIA, L.; PIQUÉ, R.; ANTOLÍN, F. (2013): El pecio de Binissafúller. Estado de las investigaciones, I Congreso de Arqueología Náutica y Subacuática Española (X. Nieto, M. Bethencourt, coords.), Cartagena, 67-85.

ALlEPUZ, X. (2001): Introducció al poblament ibèric a la Plana de l'Arc (Castelló), Castelló.

ALTUR, V. J. (dir.) (2008): Informe de sostenibilidad ambiental del Plan General del Municipio de Sergorbe (Castellón), Castelló. Trabajo inédito.

ÁLVAREZ, N.; BALLESTER, C.; ESPÍ, I.; MÁÑEZ, J.; MARÍN, C.; PASCUAL, G.; RIBERA, A. (2003): Las cerámicas de tres nuevos depósitos votivos de fundación de las excavaciones de l'Almoina (Valencia), Congrès de la Societé Française de l'Étude de la Céramique Ancienne en Gaule. Vienne (Francia), Marsella, 369-396.

ARANEGUI, C. (2004): Sagunto. Oppidum, emporio y municipio romano, Barcelona.

ARANEGUI, C.; MARTÍ, M. A. (1995): Cerámicas procedentes de un alfar ibérico localizado en el Pla de Piquer (Alfara de Algimia), cerca de Sagunt (València), Saguntum-PLAV 19, 201-223.

ARASA, F. (1992): La romanización del Alto Palancia según la epigrafía, Segorbe.

ARASA, F.; ROSELLÓ, V. M. (1995): Les vies romanes del territori valencià, València.

BALSERA, R. (2007): Una variante layetana de ánfora ibérica: El subtipo de espaldas sobreelevadas y boca hundida (finales s. III-principios del s. I a. C.), Saguntum-PLAV 39, 157-164.

BONET, H. (1995): El Tossal de Sant Miquel de Llíria. La antigua Edeta y su territorio, València.

BONET, H.; MATA, C. (1997): La cerámica ibérica del siglo V a.C. en la Edetania, Recerques del Museu d'Alcoi 6, 31-48.

BONET, H.; MATA, C. (2002): El Puntal dels Llops. Un fortín edetano, Serie Trabajos Varios. S.I.P. 99, València. 
BURRIEL, J. M. (1997): Aproximació a la cerámica ibérica d'El Tos Pelat de Montcada, L'Horta Nord de València, Recerques del Museu d'Alcoi 6, 71-86.

BUSQUIER, J. D. (coord.) (2011): Memoria Final de trabajos arqueológicos. Prospección arqueológica. Corredor ferroviario de altas prestaciones Cantábrico-Mediterráneo: Tramo Teruel-Sagunto, Alacant. Trabajo inédito.

CASABÓ, J. A.; GONZÁLEZ, A.; VIÑUELA, A. (2000): Ocupando un territorio. Ensayo sobre los modelos teóricos de explotación del territorio de las sociedades cazadoras-recolectoras del tardiglaciar y holoceno inicial en el vallo medio del río Palancia (Castellón-Valencia), QPAC 21, 5-26.

CASABÓ, J. A.; ROVIRA, M. L. (2002): El Paleolítico Medio en el Valle del río Palancia, Saguntum-PLAV 34, 9-28.

COLL, J. (2000): Aspectos de tecnología de producción de la cerámica ibérica, Íbers. Agricultors, artesans i ramaders. III Reunió sobre Economia en el mon ibèric (C. Mata, G. Pérez Jordà, eds.) Saguntum-PLAV Extra-3, València, 191-209.

CURA, M.; FALOMIR, F. (2002-2003): Excavacions arqueològiques a la Torre del Prospinal (Pina de Montalgrao, Alt Palància, Castelló). La campanya del 2001, QPAC 23, 173-186.

DÍES, E. (1991): Funcionalidad de las torres en las fortificaciones del Camp de Turia (Valencia): defensa, vigilancia y señales, Fortificacions. La problemática de l'Ibèric ple (segles IV-III a. C.). Simposi Internacional d'Arqueologia Ibérica, Manresa, 171-178.

DILOLI, J. (2008): La ceràmica ibèrica a torn al curs inferior de l'Ebre (Baix Ebre, Montsià i Baix Maestrat). Un assaig de classificació, Cypsela 17, 233-252.

DUARTE, F. J.; GARIBO, J.; MATA, C.; VALOR, J. P.; VIDAL, X. (2000): Tres centres de producció terrissera al territori de Kelin, Íbers. Agricultors, artesans i ramaders. III Reunió sobre Economia en el mon ibèric (C. Mata, G. Pérez Jordà, eds.), Saguntum-PLAV Extra-3, València, 231-239.

ÉCHALLIER, J. C.; MONTAGU, J. (1985): Données quantitatives sur la préparation et la cuisson en four à bois de reconstitutions actuelles de poteries grecques et rornaines, DAM 8, 141-145. DOI: https://doi.org/10.3406/dam.1985.962

FARNÓS, A. (coord.) (1995): Gúdar-Maestrazgo. Cuadernos de la Trashumancia 14. Madrid.

FERNÁNDEZ, H. (coord.) (2008a): Memoria del seguimiento arqueológico y etnológico de la línea de evacuación eléctrica. Tramo 1 (Ap. 1-92). Zona 6 del Plan Eólico Valenciano, Valencia. Trabajo inédito.

FERNÁNDEZ, H. (coord.) (2008b): Memoria del seguimiento arqueológico y etnológico de la línea de evacuación eléctrica. Tramo 2 (Ap.93-116). Zona 6 del Plan Eólico Valenciano, Valencia. Trabajo inédito.

FLETCHER, D. (1940): El poblado ibérico de Rochina, Atlantis XV, 125-140.

FLETCHER, D. (1954): La cueva y el poblado de La Torre del Mal Paso (Castellnovo, Castellón), APL V, 187-224.
FLETCHER, D.; MESADO, N. (1967): El poblado ibérico de El Solaig (Bechí, Castellón), Serie Trabajos Varios. S.I.P. 33, València.

GARCÍA, J. M.; MORAÑO, I. (1998): Aportaciones al estudio del poblamiento protohistórico en la provincia de Castellón: dos nuevos yacimientos, QPAC 19, 1-15.

GARIBO, J. (2006): La ceràmica ibèrica de Valentia. València. Trabajo inédito.

GIL-MASCARELL, M.; ARANEGUI, C. (1977): El poblamiento del Bajo Palancia en época ibérica, Saguntum-PLAV 12, 191-242.

GONZÁLEZ ALCALDE, J. (2002-2003): Cuevas-refugio y cuevas-santuario en Castellón y Valencia: espacios de resguardo y entornos iniciáticos en el mundo ibérico, QPAC 23, 187-240.

GONZÁLEZ-ALCALDE, J. (2009): Una aproximación cultural a los vasos caliciformes ibéricos en cuevas-santuario y yacimientos de superficie, QPAC 27, 83-108.

GUSI, F.; DIAZ, M.; OLIVER, A. (1991): Modelos de fortificación ibérica en el norte del País Valenciano, Actes del Simposi Internacional d'Arqueologia Ibèrica, 79-102.

GUÉRIN, P. (2003): El Castellet de Bernabé y el horizonte ibérico pleno edetano, Serie Trabajos Varios. S.I.P. 101, València.

JÁRREGA, R. (1998): El poblamiento romano en la comarca de El Alto Palancia (Castellón). Estado actual de nuestros conocimientos, QPAC 19, 349-369.

JÁRREGA, R. (2000): El Alto Palancia en época romana, Castelló.

JÁRREGA, R. (2001): La vía romana de Saguntum a Caesaraugusta en la comarca del Alto Palancia. Estudio Arqueológico, Millars: Espai i història 24, 35-58.

JUAN-TRESSERAS, J. (2000): La cerveza: un producto de consumo básico entre las comunidades ibéricas del NE peninsular, Íbers. Agricultors, artesans i ramaders. III Reunió sobre Economia en el mon ibèric (C. Mata, G. Pérez Jordà, eds.), Saguntum-PLAV Extra-3, València, 139-145.

JUNYENT, E.; BALDELLOU, V. (1972): Estudio de una casa Ibérica en el poblado de «Mas Boscá», Badalona (provincia de Barcelona), Príncipe de Viana 126-127, 5-68.

LÓPEZ SEGUÍ, E. (2000): La alfarería ibérica en Alicante. Los alfares de la Illeta dels Banyets, La Alcudia y El Tossal de Manises, Íbers. Agricultors, artesans i ramaders. III Reunió sobre Economia en el mon ibèric (C. Mata, G. Pérez Jordà, eds.). Saguntum-PLAV Extra-3, València, 241-248.

LOZANO, L. (2006): El centro artesanal iberorromano de La Maralaga (Sinarcas, Valencia), Saguntum-PLAV 38, 133-148.

LLOBREGAT, E. (1972): La colección Andrés Monzó Nogués. Materiales para el estudio del poblamiento antiguo de la provincia de Valencia, APL XIII, 55-80.

LLOP, J. (2015): Estudio histórico-arquitectónico del despoblado ibérico de "La Rochina" (Sot de Ferrer, Castellón), Trabajo Fin de Máster inédito, València.

MARTÍ, M. A. (1998): El área territorial de Arse-Saguntum en época ibérica, València. 
MARTÍ, R.; SELMA, S. (2008): El jaciment antic i la talaia medieva de Torre de Mal Paso (Castellnovo, Castelló), Fars de l'islam antigues alminares d'Al-Andalus, Barcelona, 167-186

MATA, C. (2002): Límites y fronteras en la Edetania, Primi Popoli d'Europa. Proposte e riflessioni sulle origini della civiltò nell'Europa mediterranea, Florencia, 221-238.

MATA, C.; BONET, H. (1992): La cerámica ibérica: ensayo de tipología, Homenaje a Enrique Pla Ballester, Serie Trabajos Varios. S.I.P. 89, València, 117-174.

MESADO, N. (1974): Vinarragell (Burriana, Castellón), Serie Trabajos Varios. S.I.P. 46, València.

MIRÓ, J. (1984): Algunas consideraciones sobre las ánforas Mañá B-3, Pyrenae 19-20, 157-189.

MONEO, M. T. (2003): Religio Iberica. Santuarios, ritos y divinidades (siglos VII-I a. C.), Madrid.

MORET, P. (1996): Les fortifications ibériques, de la fin de l'âge du bronze à la conquête romaine, Madrid.

OLIVER, A.; BLASCO, M.; FREIXA, A.; RODRÍGUEZ, P. (1984): El proceso de iberización en la plana litoral del sur de Castellón, CPAC 10, 63-110.

PALOMAR, V. (1984): El poblamiento prehistórico del Alto Palancia: estado actual de nuestros conocimientos, Castelló.

PALOMAR, V. (1986): La cueva del Murciélago (Altura, Castellón): $1^{\mathrm{a}}$ y $2^{\mathrm{a}}$ campaña de excavaciones, CPAC 12, 45-98.

PALOMAR, V. (1989): La Cueva del Murciélago (Altura, Castellón), $1^{\mathrm{a}}$ y $2^{\mathrm{a}}$ campaña de excavaciones, XIX CNA 1, Zaragoza, 78

PALOMAR, V. (1991): Las dataciones de c-14 de la cueva del Murciélago (Altura, Castellón), CPAC 15, 419-436.

PALOMAR, V. (1995): Un nuevo exvoto ibérico de bronce localizado en el Alto Palancia, CPAC 16, 267-272.

PALOMAR, V.; OLIVER, A. (1980): Inscripciones ibéricas del Alto Palancia: notas para el estudio de la latinización en Castellón, QPAC 7, 119-126.
PALOMAR, V.; OLIVER, A. (1985): La Cueva de la Cerdaña (Pina de Montalgrao, Castellón), CPAC 11, 141-156.

PASCUAL, P.; RIBERA,A. (1991): Memoria de la quinta campaña de excavaciones en el solar de l'Almoina, València. (Inédita).

PÉREZ MÍNGUEZ, R. (2006): Aspectos del mundo rural romano en el territorio comprendido entre los ríos Turia y Palancia, Serie Trabajos Varios. S.I.P. 106, València.

RIBERA, A. (1982): Las ánforas prerromanas valencianas (fenicias, ibéricas y púnicas), Serie Trabajos Varios. S.I.P. 73 València.

RIBERA, A. (1993): Estudi arqueològic de València a l'època romano-republicana, Valencia. Tesis doctoral inédita.

RIBERA, A.; TSANTINI, E. (2008): Las ánforas del mundo ibérico, Cerámicas hispanorromanas. Un estado de la cuestión (D. Bernal, A. Ribera, eds.), Cádiz, 617-634.

SANCHÍS, C. (2000): La carretera de Aragón (Sagunt-Teruel): 1791-1862, Cuadernos de Geografía 67-68, 167-189.

SANMARTÍ, J.; BRUGUERA, R.; MIÑARRO, M. (2004): Las ánforas ibéricas de la costa de Cataluña, DAM 27, 379-403.

SARRIÓN, I. (1978): El poblado ibérico de Peña de Las Majadas, El Toro, Castellón de la Plana, APL XV, 177-189.

SORIA, L.; MATA, C. (2015): Marcas y epígrafes sobre ánforas de época ibérica. II, Lucentum 34, 145-172.

TSANTINI, E. (2007): Estudi de la producció i la distribució d'àmfores ibèriques en el Nord-Est peninsular a través de la seva caracterització arqueomètrica, Barcelona. Tesis doctoral inédita.

UROZ, J. (1983): La regio edetania en época ibérica, Alacant.

VICIACH, A.; ROVIRA, M. L. (e. p.): Restauració d'un tram de Muralla i de dues Torres del Poblat de Sant Josep, La Vall d'Uixó, IV Jornades d'Arqueologia de la Comunitat Valenciana. Investigació, conservació i difusió del Patrimoni Cultural, Castelló. 